\title{
Possible use of alcohol vapors by inhalation in the treatment of COVID-19 in clinical ill patients
}

\author{
Saif ul Islam* \\ Adventist Hospital, United States of America \\ Received: 22 July 2020 \\ Accepted: 01 September 2020 \\ *Correspondence: \\ Dr. Saif ul Islam, \\ E-mail: saif_1104@yahoo.com \\ Copyright: (C) the author(s), publisher and licensee Medip Academy. This is an open-access article distributed under \\ the terms of the Creative Commons Attribution Non-Commercial License, which permits unrestricted non-commercial \\ use, distribution, and reproduction in any medium, provided the original work is properly cited.
}

\section{INTRODUCTION}

Ethyl alcohol or ethanol is an effective chemical in denaturing enveloped viruses in vitro, including SARSCoV-2. It is found that exposure of only 30 seconds is sufficient to deactivate the virus. Alcohol has never been used for the treatment of viral lung infection. However, alcohol vapors by inhalation are used for acute respiratory distress syndrome and alcohol withdrawals.

This article aims to discuss the possibility of using the alcohol vapors by inhalation in the treatment of COVID19 and other viral lung infection. So far, alcohol vapors by inhalation have never been used before to treat viral infection in the lungs. Therefore, there is no data, or clinical trials are available to report the finding, but theoretically, it seems a possibility.

As the days are passing, pandemic COVID-19 is getting worst. Every day thousands of people are getting infected and are dying with no relief or cure in sight. According to WHO, there is a high possibility of reappearing the infection this winter. We are hoping to find the treatment before it reappears and causes havoc. The main cause of death associated with COVID-19 is an acute severe respiratory syndrome, which results in shock and multiple organs failure. ${ }^{1}$ Several drugs and other treatment methods have tried, but none have shown any promising result in eradicating the virus. The availability of vaccines is 8-12 months from now, and we do not know how effective it would be! $!^{2,3}$

SARS-CoV-2 is a positive-sense single-stranded RNA enveloped virus which is quickly inactivated by alcohol in vitro. According to the $\mathrm{CDC}, 60 \%$ ethyl alcohol inactivates the virus within 30 seconds. Some studies have shown that concentration as low as $30 \%$ alcohol is effective in the deactivation of the coronavirus. ${ }^{4}$ There is no study available to describe the effectiveness of alcohol vapors by inhalation in the treatment of viral or bacterial infection in the lungs. However, few studies were available where alcohol vapors were used as an inhalation for pulmonary edema. In his study, Dr. Aldo used alcohol vapors of various concentrations ranging from $30 \%$ to $70 \%$, driven by oxygen for the treatment of acute severe pulmonary edema that was resisted to other traditional therapy. It is believed that alcohol vapors affect surface tension and act as an antifoaming agent, and the patient can breathe easier. In conclusion, Dr. Aldo wrote that alcohol vapors were tolerated well by the patients. ${ }^{5}$ In the 1950 's it was common to use alcohol vapors by inhalation for the treatment of acute severe pulmonary edema.

Another study conducted by Dr. Peng and colleagues used alcohol vapors by inhalation for the treatment of postoperative alcohol withdrawal in the esophageal cancer patient. He used $100 \mathrm{ml}$ of $60 \%$ ethyl alcohol added to an oxygen humidification bottle. In conclusion, he wrote about the effectiveness of the treatment. ${ }^{6}$ Another study conducted by Dr. Kong and colleagues reviewed the effectiveness and safety of alcohol vapors by inhalation in postoperative patients $(n=51)$ for alcohol withdrawal. In summary, he wrote that an alcohol vapor by inhalation is an effective and safe method for short term treatment. ${ }^{7}$ Besides medical uses, alcohol vapors by inhalation were common recreational methods during the 1980 s and are one of the ingredients in e-cigarette. ${ }^{8}$ 
SARS-CoV-2 has a propensity for lung epithelial cells. Sglycoprotein on virus envelope interacts with ACE2 receptors and enters into human cells via fusing with the host membrane and by endocytosis. Inside the cytoplasm, single-stranded viral RNA attached to the host ribosome and translates RNA polymerase, which directs the host ribosome to copy viral RNA genome to viral proteins and negative-sense RNA, which copy to positive-sense RNA. Nonstructural viral protein guides structural protein to Golgi apparatuses where viral proteins get finishing modification and organized into virions. These virions bud out the cells and infect new cells. It is unknown if alcohol vapors by inhalation could inactivate the viruses inside the lung cells.

When ethanol is vaporized into the lung, some of it is absorbed into the bloodstream, some exhale out via expiration, and some enter into the lung cells. Inside the lung cells, alcohol is metabolized by various pathways. ${ }^{9}$ However; the major pathway is the cytosolic enzyme, alcohol dehydrogenase, which converts the alcohol to acetaldehyde. Acetaldehyde is a very active intermediate, which is further oxidized by the mitochondrial enzyme aldehyde dehydrogenase to acetate. ${ }^{9}$ The rate of conversion from alcohol to acetate is a concentration and time-dependent. Viruses present in the lumen of bronchioles, bronchi, alveoli, oropharynx, and nasopharynx will be deactivated by the direct exposure of alcohol vapors and decrease the extracellular viral load and viral shedding.

In COVID-19, most of the lung damage is caused by overacting the self-immune system. Lung infection triggers an inflammatory response that activates a bunch of pro-inflammatory markers such as cytokines, IL6, IL1b, macrophages, leukocytes, NK, fibroblast, neutrophils, etc. The result is protein-rich fluid in the alveoli and thickening of the basement membrane, which leads to the diffusion of oxygen from the lung to blood very difficult. Nebulizing with alcohol vapors using oxygen as the driving force would make breathing easier. ${ }^{5-7}$ Vapors improve the gas exchange by decreasing the surface tension and act as an antifoaming agent.

There is a possibility that some of the lung epithelial cells might get damaged by the inhalation of alcohol vapors. But the damage would depend upon the concentration and duration of alcohol exposure. A brief contact and possible low concentration of ethyl alcohol, sufficient to inactivate the virus, may not have a very harmful effect on the human lung cells. It is important to point out that the authors of previous studies concluded that most of the patients tolerated alcohol vapors well.

\section{CONCLUSION}

The novel idea of using alcohol vapors by inhalation with oxygen could decrease the viral load, virus shedding, and ease in breathing in ARDS patients. Combination therapy with antiviral drugs might give a better result. There is a need for further study and clinical research.

\section{REFERENCES}

1. Vincent $\mathrm{J}$, Taccone F. Understanding pathways to death in patients with COVID-19. Lancet Respir Med. 2020;8(5):430-2.

2. Levison M. Commentary Coronavirus Update, Merck Manual, Professional edition. Available at: https://www.merckmanuals.com/professional/ news/editorial/2020/03/26/17/16/covid19-update-2. Accessed on 1 April 2020.

3. Centre for disease control and prevention. Available at: WWW.CDC.gov/coronavirus 2019ncov/hcp/therapeutic-option. Accessed on 1 April 2020.

4. Kempf G. Efficacy of ethanol against viruses in hand disinfection. Journal of Hospital Infection. 2018;98(4)331-8.

5. Aldo A. Treatment of pulmonary edema. JAMA. 1954;1(154):62.

6. Zheng P, Yang Z, Zhao Y, Liu Y, Zhang L, Shao G, et al. Inhalation of alcohol vapor driven by oxygen is a useful therapeutic method for postoperative alcohol withdrawal syndrome in a patient with esophageal cancer: a case report. Alcohol and Alcoholism. 2011;46(4):424-6.

7. Kong F, Zhang M, Wang H, Liu D, Wu Y, Chai N, et al. Symptom-triggered alcohol vapor inhalation for postoperative alcohol withdrawal syndrome in patients with gastroesophageal carcinoma. JBUON. 2017;22(5):1266-71.

8. Alcohol Inhalation. Available at: https://en. wikipedia.org/wiki/Alcohol_inhalatio. Accessed on 1 April 2020.

9. Kaphalia L, Calhoun WJ. Alcoholic lung injury: metabolic, biochemical and immunological aspects. Toxicol Lett. 2013;222(2):171-9.

Cite this article as: Islam S. Possible use of alcohol vapors by inhalation in the treatment of COVID-19 in clinical ill patients. Int $\mathrm{J}$ Basic Clin Pharmacol 2020;9:1627-8. 